\title{
OCORRÊNCIA DE DOENÇAS CAUSADAS POR MOLICUTES E POR VÍRUS EM MILHO NAS PROVÍNCIAS DE TUCUMÁN E DE CÓRDOBA NA ARGENTINA
}

\author{
MARIA P. GIMÉNEZ PECCI ${ }^{1}$, ELIZABETH DE OLIVEIRA² ${ }^{2}$ RENATO O. RESENDE ${ }^{3}$, \\ IRMA G. LAGUNA ${ }^{1}$, LUÍS R CONCI ${ }^{1}$, ANSELMO AVILA ${ }^{1}$, PATRÍCIA HERRERA, \\ ERNESTINA GALDEANO ${ }^{1}$, EDUARDO VIRLA ${ }^{4} \&$ CLÁUDIA F. NOME ${ }^{1}$
}

\begin{abstract}
'Instituto de Fitopatologia y Fisiologia Vegetal - INTA, Córdoba, Argentina, e-mail: beth@cnpms.embrapa.br, Fax: (31) 3779-1088; ${ }^{2}$ Embrapa Milho e Sorgo, Cx. Postal 151, 35701-970; ${ }^{3}$ Departamento de Biologia Celular, Universidade de Brasília; ${ }^{4}$ PROIMI, Tucumán, Argentina
\end{abstract}

(Aceito para publicação em 18/04/2002)

Autor para correspondência: Elizabeth de Oliveira

GIMÉNEZ PECCI, M.P., OLIVEIRA, E., RESENDE, R.O., LAGUNA, I.G., CONCI, L.R., AVILA, A., HERRERA, P., GALDEANO, E., VIRLA, E. \& NOME, C.F. Ocorrência de doenças causadas por molicutes e por vírus nas Províncias de Tucumán e de Córdoba na Argentina. Fitopatologia Brasileira 27:403-407. 2002.

\section{RESUMO}

A incidência de doenças causadas por molicutes e por vírus foi avaliada em lavouras de milho (Zea mays) nas Províncias de Tucumán e de Córdoba, na Argentina, em fevereiro de 2000. Na Província de Tucumán verificou-se que $44 \%$ das lavouras apresentaram altos níveis de incidência de plantas com sintomas de enfezamentos causados por molicutes (50 a 100\%), em altitudes variando de 300 a $2.000 \mathrm{~m}$. A presença de fitoplasma e de espiroplasma foi confirmada em amostras de folhas de plantas com sintomas de enfezamentos, através dos testes de PCR e de "Western blotting". Constatou-se, porém, que a eficiência desses testes para detecção destes patógenos, quando os sintomas apresentados pelas plantas eram muito acentuados, foi da ordem de $70 \%$, e de apenas $30 \%$ quando os sintomas eram menos acentuados. Na localidade Jesus Maria, foram encontradas plantas apresentando acentuado nanismo, folhas estreitas e com deformações. Dentre quatro amostras destas plantas, submetidas a testes de PCR, em duas foi detectada a presença de fitoplasma, possivelmente d istinto do "Maize Bushy Stunt Phytoplasma". A cigarrinha Dalbulus maidis, inseto vetor dos molicutes, foi encontrada apenas em Tucumán, estando ausente em Córdoba. O Mal de Rio Cuarto virus foi detectado em seis lavouras em Córdoba, e em três em Tucumán. A cigarrinha Delphacodes kuscheli foi detectada em todas as lavouras em Córdoba, e em apenas três lavouras em Tucumán. O Maize dwarf mosaic virus foi detectado em cerca de $60 \%$ das lavouras amostradas nas duas Províncias e o Maize rayado fino virus em apenas uma localidade em Tucumán.

Palavras-chave adicionais: Fitoplasma, Espiroplasma, Mal de Rio Cuarto virus, Maize dwarf mosaic virus, Maize rayado fino virus.

\section{ABSTRACT \\ Occurrence of corn stunt diseases and maize viruses in the Provinces of Tucumán and Córdoba in Argentina}

The incidence of "corn stunt diseases" and maize (Zea mays) viruses was evaluated in maize fields located at the Provinces of Tucumán and Córdoba in Argentina in February 2000. A high number of plants infected with "corn stunt disease" were observed in Tucumán (up 50 to $100 \%$ ) in $44 \%$ of maize crops surveyed in areas varying from up 300 to $2000 \mathrm{~m}$ high. The presence of Maize Bushy Stunt Phytoplasma (MBSP) and Corn Stunt Spiroplasma (CSS) was confirmed by PCR and Western blotting tests. In plants showing typical symptoms of MBSP or CSS, the pathogens were detected in $70 \%$ of the samples. However, when symptoms were weak, the efficiency of detection dropped to approximately $30 \%$. In Rio Cuarto, Province of Córdoba, the presence of phytoplasma was detected only in three plants showing red leaf symptoms. In Jesus Maria locality, plants showing symptoms different from those caused by MBSP, were demonstrated to be infected by phytoplasma when analyzed by PCR using universal primers. The leafhopper Dalbulus maidis, vector of MBSP and CSS, was found only in Tucumán. The Mal de Rio Cuarto virus (MRCV) was found in six maize fields in Córdoba and in three maize fields located at 1970 to $2.000 \mathrm{~m}$ high in Tucumán. The plant hopper Delphacodes kuscheli, vector of MRCV, was found in both provinces sampled. The Maize dwarf mosaic virus (MDMV) was found in $60 \%$ of maize crops in both Provinces and the Maize rayado fino virus (MRFV)was found only in one location in Tucumán.
O enfezamento pálido (Corn Stunt) e o enfezamento vermelho (Maize Bushy Stunt) do milho (Zea mays L.) causados, respectivamente, por Spiroplasma kunkelli Whitcomb e por fitoplasma (classe Mollicutes) são de grande importância em regiões tropicais e subtropicais nas Américas, onde ocorrem em surtos epidêmicos causando danos severos na produção de grãos de milho (Hruska et al., 1996; Oliveira et al., 1998). Esses molicutes e o Maize rayado fino virus (MRFV) família Tetraviridae, gênero Marafivirus são transmitidos de forma persistente, pela cigarrinha Dalbulus maidis DeLong \& Wolcott (Nault, 1980).

O Mal de Río Cuarto virus (MRCV) família Reoviridae, gênero Fijivirus transmitido de forma persistente pela cigarrinha Delphacodes kuscheli Fennah tem causado 
danos significativos na produção de milho, na Argentina. Outros vírus de importância para essa cultura, atualmente relatados na Argentina, incluem o Maize dwarf mosaic virus (MDMV) família Potyviridae, gênero Potyvirus e, de menor importância, o Barley yellow dwarf virus (BYDV) família Luteoviridae, gênero Luteovirus, ambos transmitidos por pulgões (Lenardon, 1999).

O objetivo desse trabalho foi avaliar a ocorrência de doenças causadas por molicutes e por vírus em milho, em regiões com distintas condições climáticas, na Argentina, e associar os sintomas observados nas plantas à presença dos patógenos detectados através de testes em laboratório.

Foram realizadas avaliações em 32 lavouras de milho situadas em altitudes entre 300 e $2.000 \mathrm{~m}$ na Província de Tucumán e em altitudes entre 420 e $630 \mathrm{~m}$ na Província de Córdoba. Essas lavouras encontravam-se em estádio fenológico variando de 5 a 9 (Francelii \& Dourado Neto, 1996).

A ocorrência dos enfezamentos e viroses foi determinada em campo através dos sintomas apresentados pelas plantas. Para confirmação dos diagnósticos feitos em campo, foram coletadas amostras de folhas de plantas sintomáticas e, em laboratório, feita a detecção de vírus e molicutes. Foram utilizados os testes:DAS-ELISA, para detecção do MRCV e para detecção de MDMV; PCR para detecção de fitoplasma; "Western blotting" para detecção de espiroplasma; dsRNA e RT-PCR para detecção de MRFV.

Para associar os sintomas apresentados pelas plantas de milho à presença de fitoplasma, espiroplasma e MRCV, foram selecionadas 23 amostras de plantas com sintomas de enfezamentos, provenientes da Província de Tucumán, que simultaneamente foram submetidas aos testes de PCR para detecção de fitoplasma, de "Western blotting" para detecção de espiroplasma e de DAS-ELISA para detecção de MRCV. Como sintomas típicos de MBSP foram considerados a proliferação de espigas e/ou avermelhamento nas margens e ápice das folhas; como sintomas típicos de CSS considerou-se a presença de estrias esbranquiçadas na base das folhas, amarelecimento generalizado da planta e, algumas vezes, presença de avermelhamento apenas na folha apical da planta. Quando as plantas apresentavam sintomas intermediários entre esses descritos acima, foram consideradas possivelmente infetadas simultaneamente pelos dois patógenos (CSS ou MBSP). A infecção por MRCV foi considerada quando as plantas apresentavam deformações foliares e/ou presença de enações sobre as nervuras, na face inferior das folhas.

Na Província de Córdoba, na localidade denominada Jesús María, foram coletadas amostras de folhas em plantas de milho apresentando acentuado nanismo, folhas estreitas e enrijecidas, formação anômala de espigas no pendão, sem avermelhamento foliar e, em laboratório, estas foram submetidas a testes para detecção de molicutes.

Com auxílio de uma rede entomológica foram coletadas amostras de insetos em todas as lavouras avaliadas. Os insetos foram preservados em álcool $70 \%$ e, posteriormente, examinados sob microscópio estereoscópico verificando-se a presença ou ausência de cigarrinhas das espécies D. maidis e D. kuscheli.

\section{PCR para detecção de fitoplasma}

Foram utilizados os iniciadores: P1 - 5'AAGAGTTTG ATCCTGGCTCAGGATT3 e Tint - 5'TCAGGCGTGTGCTC TAACCAGC3' e a metodologia descrita Smart et al. (1996). As amostras em que foram detectadas bandas foram também analisadas utilizando-se iniciadores para detecção de MBSP, conforme descrito por Harrison et al. (1996).

\section{Western blotting para detecção de espiroplasma}

As amostras foram submetidas à eletroforese em minigel de poliacrilamida $12,5 \%$ e transferidas, via úmida, para membrana de nitrocelulose $0,45 \mu \mathrm{m}$. Após bloqueio dos sítios inespecíficos, foi incubada por uma noite em solução de leite desnatado com o anticorpo primário e, por $2 \mathrm{~h}$ em TTBS contendo o anticorpo secundário, conjugado com fosfatase alcalina. A revelação foi feita com NBT e BCIP. O protocolo utilizado foi baseado em Hampton et al. (1990). Utilizou-se IgG anti CSS fornecida à Embrapa Milho e Sorgo, pela Pionneer Hi Bred International (Johnston-EUA), que tem sido utilizada para detecção desse patógeno no Brasil (Oliveira et al., 1998).

\section{DAS-ELISA para detecção de MRCV e de MDMV}

Amostras de folhas foram maceradas em tampão PBS $+0,05 \%$ de Tween 20 seguindo-se o procedimento para o teste DAS-ELISA conforme descrito por Giménez Pecci et al. (1991). Foram utilizados antissoros específicos para o MRCV, e para o MDMV, produzidos no INTA/Córdoba.

\section{RT-PCR para detecção de MRFV}

Para a extração de dsRNA, folhas com sintomas típicos de MRFV foram processadas como descrito por Valverde et al. (1990). Foi feita amplificação por RT-PCR, de acordo com a metodologia descrita por Hammond et al. (1997), usandose os iniciadores: MRFV-09 (5' CCTCTTCCTGATCCTCCT CGTGTGCTGGAGACG 3') e MRFV-10 (5' GCCCACAGG TCTTATGGCCGACCTGCTACC 3'). Estes iniciadores amplificam um fragmento de $633 \mathrm{pb}$ correspondente a uma porção do gene da capa protéica (nt 3-533 = 531 pb) e à região 3' não traduzida do vírus (99 pb).

Na Província de Tucumán constatou-se alta incidência de plantas com sintomas de enfezamentos, atingindo níveis da ordem de 50 a $100 \%$, na maioria das lavouras avaliadas (Tabela 1). Essas doenças foram encontradas tanto em altitudes em torno de $300 \mathrm{~m}$ quanto em torno de $2.000 \mathrm{~m}$. Em amostras analisadas dessas plantas foi confirmada a presença de espiroplasma e de fitoplasma. Em todas as lavouras avaliadas, em Tucumán, foi detectada a presença da cigarrinha $D$. maidis. Entre as condições favoráveis à alta incidência dessas doenças, destacam-se as climáticas que permitem o cultivo de milho durante o ano todo, favorecendo a perpetuação dos patógenos nas plantas e no seu vetor, e a susceptibilidade das variedades e híbridos 
TABELA 1 - Ocorrência de doenças causadas por molicutes e por vírus em milho (Zea mays) e de cigarrinhas Dalbulus maidis e Delphacoides kuscheli, em diferentes localidades nas Províncias de Tucumán e de Córdoba, na Argentina

\begin{tabular}{|c|c|c|c|c|c|c|c|c|c|}
\hline \multirow{2}{*}{ Local } & \multirow{2}{*}{$\begin{array}{c}\text { Estadio } \\
\text { Fenológico }\end{array}$} & \multirow{2}{*}{ D. Kuscheli } & \multirow{2}{*}{ D. maidis } & \multicolumn{5}{|c|}{ Sintomas ${ }^{1,2}$} & \multirow{2}{*}{$\begin{array}{c}\text { Incidência (\%) } \\
\text { CSS + MBSP }\end{array}$} \\
\hline & & & & MRFV & CSS & MBSP & MRCV & MDMV & \\
\hline \multicolumn{10}{|l|}{ TUCUMÁN } \\
\hline San Andres & 7 & - & + & - & + & + & - & + & 10 \\
\hline INTA Leales & 7 & - & + & - & + & + & - & + & 100 \\
\hline INTA Leales* & 5 & - & + & - & - & - & - & - & - \\
\hline Los Sueldos & 7 & - & + & - & + & + & - & - & 50 \\
\hline Los Bulacios & 7 & - & + & - & + & + & - & + & 100 \\
\hline La Angostura & 7 & + & + & - & + & + & + & + & 20 \\
\hline La Ovejeria & 7 & + & + & - & + & + & + & + & 5 \\
\hline El Mollar & 6 & + & + & + & - & + & + & + & 50 \\
\hline Santa Lucía & 7 & - & + & - & + & + & - & + & 100 \\
\hline Trancas & 7 & - & + & - & + & + & - & - & 100 \\
\hline Trancas & 7 & - & + & - & - & + & - & + & $<5$ \\
\hline Benjamin Paz & 6 & - & + & - & - & + & - & - & $<1$ \\
\hline Benjamin Paz & 7 & - & + & - & + & + & - & - & 5 \\
\hline Vipos & 7 & - & + & - & + & + & - & + & 50 \\
\hline El Cadillal* & 5 & - & + & - & - & - & - & - & - \\
\hline El Cadillal* & 6 & - & + & - & + & + & - & + & - \\
\hline \multicolumn{10}{|l|}{ CÓRDOBA* } \\
\hline Rio Cuarto & 6 & + & - & - & - & + & + & + & - \\
\hline Sampacho & 6 & + & - & - & - & - & + & + & - \\
\hline Jesús Maria & 7 & + & - & - & - & - & + & + & - \\
\hline Totoral & 7 & + & - & - & - & - & - & + & - \\
\hline Totoral & 6 & + & - & - & - & - & - & + & - \\
\hline Totoral & 6 & + & - & - & - & - & - & + & - \\
\hline Totoral & 6 & + & - & - & - & - & - & + & - \\
\hline Totoral & 8 & + & - & - & - & - & - & - & - \\
\hline S.J. de la Dormida & 8 & + & - & - & - & - & + & - & - \\
\hline El Simbolar & 8 & + & - & - & - & - & - & - & - \\
\hline El Simbolar & 7 & + & - & - & - & - & - & + & - \\
\hline Las Peñas & 6 & + & - & - & - & - & - & + & - \\
\hline V. Totoral & 9 & + & - & - & - & - & + & - & - \\
\hline V. Totoral & 9 & + & - & - & - & - & - & - & - \\
\hline Puerto Caroya & 9 & + & - & - & - & - & + & - & - \\
\hline General Paz & 6 & + & - & - & - & - & - & - & - \\
\hline
\end{tabular}

${ }^{1} \mathrm{MRFV}=$ Maize rayado fino virus; $\mathrm{CSS}=$ Corn Stunt Spiroplasma; $\mathrm{MBSP}=$ Maize Bushy Stunt Phytoplasma; $\mathrm{MRCV}=$ Mal de Rio Cuarto virus; $\mathrm{MDMV}=$ Maize dwarf mosaic virus; * incidência de CSS e MBSP não avaliada;

${ }^{2}(+)=$ presença; $(-)=$ ausência.

cultivados na região.

A virose causada pelo MRFV foi detectada em apenas uma localidade na Província de Tucumán (Tabela 1). Dentre as extrações de dsRNA feitas utilizando-se amostras de folhas com sintomas desta virose, apenas uma apresentou perfil de bandas. A presença desse vírus foi confirmada também através das análises de RT-PCR. Esse é o segundo relato de infecção do MRFV na Argentina desde quando a primeira ocorrência foi verificada em 1981 (Nome, 1984). Embora o MRFV seja disseminado pelo mesmo inseto vetor dos molicutes, pode apresentar índices de ocorrência variáveis, em safras de anos diferentes. No entanto, o monitoramento de sua incidência pode ser particularmente importante, considerando-se que pode causar danos na produção de grãos.

Por outro lado, a virose causada pelo MRCV, na Província de Tucumán, foi encontrada apenas em altitudes elevadas (1.970 a $2.000 \mathrm{~m}$ ), nas localidades La Angustura, La Ovejería e El Mollar, sendo confirmada a presença desse fijivirus nas amostras de plantas pelo teste de DAS-ELISA. A ocorrência limitada desta virose, na Província de Tucumán, pode ser provavelmente atribuída às condições ecológicas favoráveis ao desenvolvimento de seu vetor $D$. kuscheli, 
apenas quando predominam temperaturas amenas, em altitudes elevadas, à semelhança do clima na Província de Córdoba, onde o MRCV é bastante frequiente (Tabela 1). A virose causada pelo potyvirus MDMV foi confirmada em todas as amostras apresentando sintomas de mosaico, submetidas ao teste DAS-ELISA. O MDMV, mostrou-se frequiente tanto na Província de Tucumán quanto na de Córdoba (Tabela 1). Surtos desta virose podem ocorrer em função de condições como susceptibilidade da cultivar de milho, presença de afídeos vetores, e alta concentração de inóculo do vírus, proporcionada pela presença de espécies gramíneas infetadas.

Em 18 amostras de plantas com sintomas de MRCV, coletadas em lavouras de milho na Província de Córdoba e submetidas ao teste de DAS-ELISA, foi detectada a presença desse vírus em todas, confirmando os resultados previamente obtidos através da observação de sintomas apresentados pelas plantas em campo. Observa-se que esta virose encontra-se disseminada na Província de Córdoba, o que pode ser explicado pela ubiqüidade de ocorrência da cigarrinha $D$. kuskcheli (Tabela 1).

Foi detectada a presença de fitoplasma em três amostras, dentre oito amostras de plantas apresentando avermelhamento foliar, coletadas na localidade denominada Río Cuarto, ao sul da Província de Córdoba. Também foi detectada a presença de fitoplasma em plantas apresentando acentuado nanismo, folhas enrijecidas e formação anômala de espigas no pendão, sem qualquer avermelhamento foliar, provenientes da localidade Jesús María, em Córdoba. Dentre quatro amostras submetidas a testes de PCR, duas mostraramse positivas quanto à presença do patógeno. Os resultados sugerem tratar-se de fitoplasma distinto de Maize Bushy Stunt Phytoplasma, uma vez que nessas duas amostras a amplificação de bandas foi positiva quando utilizados os iniciadores universais para fitoplasma e negativa quando utilizados os iniciadores específicos para Maize Bushy Stunt Phytoplasma.

Considera-se provável que a baixa incidência de doenças causadas por molicutes, na Província de Córdoba, seja decorrente da ausência da cigarrinha D. maidis (Tabela 1), e atribui-se a ausência desse inseto às condições climáticas que limitam o cultivo do milho, seu hospedeiro quase exclusivo, a uma única época do ano. Assim, é possível que as plantas infetadas por fitoplasma, encontradas em Rio Cuarto e em Jesús María, tenham sido infetadas por outra espécie de inseto vetor, ainda desconhecida, ou por espécimens de D. maidis trazidos de outras regiões por correntes de ventos, em determinadas épocas do ano, que não proliferaram naquela região.

Quando os sintomas de enfezamentos causados por espiroplasma ou por fitoplasma eram típicos, o teste de "Western blotting" e o de PCR permitiram a confirmação da presença desses patógenos em aproximadamente $70 \%$ das amostras analisadas. Por outro lado, quando os sintomas de enfezamentos não eram tão acentuados, sendo difícil discriminá-los como típicos de infecção por fitoplasma ou de infecção por espiroplasma, foi obtido sucesso na detecção de um ou de outro desses patógenos em apenas cerca de $30 \%$ das amostras analisadas. Esse resultado pode ser possivelmente atribuído à distribuição desuniforme dos patógenos e/ ou ao seu baixo título no floema das plantas de milho. Limitação semelhante, na detecção de espiroplasma e de fitoplasma em plantas de milho foi encontrada também por Oliveira et al. (1998).

Nesse levantamento ficou evidenciada a diferenciação na predominância das doenças causadas por molicutes e pelo MRCV, nas duas Províncias. Certamente essa variação é proporcionada pela distinção climática, que restringe o desenvolvimento do vetor do MRCV nas regiões quentes de Tucumán e que restringe a sobrevivência de D. maidis, dependente da presença de milho no campo o ano todo, nas regiões de clima temperado da Província de Córdoba. Estudos visando ao manejo das doenças detectadas, devem ser considerados pois elas podem se tornar limitantes à boa produtividade de grãos de milho, quando ocorrem em surtos epidêmicos.

\section{AGRADECIMENTOS}

Os autores agradecem o apoio de VITAE e de CAPES/ SeTCIP pela concessão de recursos financeiros para suporte a projetos conjuntos Brasil/Argentina, imprescindível à realização e publicação deste trabalho. Agradecem ao Ing. Agr. León Murua, da Agencia de Extensión INTA Jesús María, pelo auxílio na localização das lavouras e ao Servicio Meteorológico Nacional, Argentina, pelo fornecimento de dados climáticos.

\section{REFERÊNCIAS BIBLIOGRÁFICAS}

FRANCELII, A.I. \& DOURADO NETO, D. Cultura do milho:aspectos fisiológicos e arranjo de água. Informações Agronômicas 73:1-4. 1996.

GIMÉNEZ PECCI, M.P., CONCI, L.R., VALDIVIA, B., CONCI, V.C., HOOP, H.E, LAGUNA, I.G \& NOME, S.F. Algunas alternativas de diagnóstico del Virus del "Mal de Río Cuarto" (Maize Rough Dwarf Virus- MRDV). Taller de Actualización sobre Mal de Río Cuarto. Pergamino 30-31 de mayo de 1991:78-86. 1991.

HAMMOND, R.W., KOGEL, R. \& RAMIREZ, P. Variability of geographically distinct isolates of maize rayado fino virus in Latin America. Journal of General Virology 78:3153-3159. 1997.

HAMPTON,R., BALL, E. \& DE BOER, S. Serological methods for detection and identification of viral na bacterial plant patogens - A laboratory Manual, St. Paul. APS Press. 1990.

HARRISON, N.A., RICHARDSON, P.A., TSAI, J.H., EBBERT, M.A. \& KRAMER, J.B. PCR assay for detection of phytoplasma associated with maize bushy stunt disease. Plant Disease 80:263-269. 1996.

HRUSKA, A.J., GLADSTONE, S.M. \& OBANDO, R. Epidemic roller coaster: maize stunt disease in Nicaragua. American Entomologist 42:248-252. 1996.

LENARDÓN, S.L. Proyeto de investigaciones en fitovirologia: 
Ocorrência de doenças causadas por molicutes e por vírus nas...

Enfermedades de los cultivos extensivos e intensivos. Córdoba: IFFIVE- INTA/JICA. 1999.

LENARDON, S.L., MARCH, G.J., NOME S.F. \& ORNAGHI, J.A. Recent outbreak of "Mal de Río Cuarto" Virus on Corn in Argentina. Plant Disease 82:448 1998.

NAULT, L.R. Maize bushy stunt and corn stunt: a comparison of disease symptoms, pathogen host ranges, and vectors. Phytopathology 70:659-662. 1980.

NOME, S.F., DAL BO, V.Y., TESSANDIER, E. \& LENARDON, S.L. Frecuencia de algunos virus de maiz en la Republica Argentina. RIA XIX:257-264. 1984.

OLIVEIRA,E., WAQUIL,J.M., FERNANDES,F.T., PAIVA,E.,
RESENDE,R.O. \& KITAJIMA,W.E. Enfezamento pálido e enfezamento vermelho na cultura do milho no Brasil Central. Fitopatologia Brasileira 23:45-47.1998.

SMART, C.D., SCHNEIDER, B., BLOMQUIST, C.L, GUERRA, L.J., HARRISON, N.A, AHRENS,U., LORENZ, K.H., SEEMÜLLER, E. \& KIRPATRICK, B.C. Phytoplasma-specific PCR primers based on sequences of the 16S-23S rRNA spacer region. Applied and Environmental Microbiology 62:29882993. 1996.

VALVERDE, R.A., NAMETH, S.T. \& JORDAN, R.L. Analysis of double-stranded RNA for plant virus diagnosis. Plant Disease 74:255-258. 1990. 